Research Article

\title{
Interfacial Bond Properties between Normal Strength Concrete and Epoxy Resin Concrete
}

\author{
Nannan Sun $\left(\mathbb{D},{ }^{1,2}\right.$ Yifan Song $\left(\mathbb{D},{ }^{1}\right.$ Wei Hou $\mathbb{D}^{1}{ }^{1}$ Hanhao Zhang $\mathbb{D}^{1},{ }^{1}$ Datong $W u,{ }^{3}$ \\ Yuan Li, ${ }^{1}$ and Yuan Gong ${ }^{3}$ \\ ${ }^{1}$ School of Highway, Chang'an University, Xi'an 710064, China \\ ${ }^{2}$ Department of Civil Engineering, Aalto University, Espoo 02150, Finland \\ ${ }^{3}$ Chengdu Datong Road Bridge Machinery Company Limited, Chengdu 611430, China
}

Correspondence should be addressed to Nannan Sun; 2017021013@chd.edu.cn and Wei Hou; chdhw@chd.edu.cn

Received 12 February 2021; Revised 16 August 2021; Accepted 16 September 2021; Published 25 September 2021

Academic Editor: Qi Cao

Copyright (c) 2021 Nannan Sun et al. This is an open access article distributed under the Creative Commons Attribution License, which permits unrestricted use, distribution, and reproduction in any medium, provided the original work is properly cited.

It is necessary to pay attention to the bonding strength of the interface between precast normal strength concrete (NSC) and castin-place epoxy resin concrete (EMR) when using EMR as a repair or filling material or an overlay in bridges' rehabilitation. However, the performances of epoxy concrete are different due to differential mix ratios; thus, the bonding properties between various epoxy resin concrete and cement concrete are not completely the same. This article investigated the interfacial bond properties between NSC and ERC by direct tensile, push-out, and slant shear test with specimens of special size and structure and observed the interfacial bond strength and corresponding failure modes. The minimum bond strength under direct tension was $0.72 \mathrm{MPa}$, while the minimum bond strength was $1.71 \mathrm{MPa}$ and $3.19 \mathrm{MPa}$ for the push-out test and slant shear test, respectively. Results indicated that the slant shear test specimens with an inclination angle of $45^{\circ}$ are not suitable for the slant shear test due to higher compressive stress. Furthermore, the cohesion and friction coefficient of interface bond strength were calculated inversely in accordance with the results obtained from the corresponding direct tensile and slant shear tests. The minimum cohesion value was $1.71 \mathrm{MPa}$, and the minimum friction coefficient value was 0.46 .

\section{Introduction}

In the mid-twentieth century, epoxy resin concrete which belongs to a type of polymer concrete was used as a commercial product in the United States $[1,2]$. In previous studies, epoxy resin often was used as an adhesive to bond two different materials, such as fiber-reinforced polymer (FRP) and concrete substrates. Tatar et al. [3] proposed that there are two different mechanisms, chemical bonding and mechanical interlock, for epoxy resin adhesives in concrete stress transference. Some scholars have studied the bonding system of FRP, epoxy resin, and concrete substrates and proposed the mechanism of adhesion from the perspective of micromechanics [4-6]. The epoxy-based material has been widely utilized for repairing of highway and bridge Portland cement concrete components in past couple of years due to its high strength, durability, short curing time, chemical resistance, and strong adhesion to different materials [7-12]. The growing number of producers and the better manufacturing techniques have resulted in a decrease in the cost of resins, which contribute to their functions not only limited to repairs but can also be used for structures. Resin concrete may be used in the production of structural components or for the production of joint or layer in traditional concrete in order to improve structural ductility [13].

Extensive research on epoxy resin concrete including its application for repair work, production and mixing ratios, and the characteristics of certain types of resin concrete was carried out. The effects of multiple factors on the setting time and mechanical behavior of the polymer concrete were investigated by Mustafa U. Haddad, David W. Fowler, and Donald R. Paul, including initiator-to-promoter ratio, initiator and promoter levels, caster temperature, temperature 
testing, type and gradation of aggregate, and effect of cold joints [14]. In a variety of curing circumstances, temperatures, and strain rate, Vipulanandan and E. Paul examined the compressive and traction characteristics of polyester and polymer concrete. They carried out the research on the curing temperature from the homeothermy to $80^{\circ} \mathrm{C}$ and the test temperature in the range of $12^{\circ} \mathrm{C}$ to $220^{\circ} \mathrm{C}$ and the strain rates were controlled in 0.01 percent to 60 percent strain per minute. They conducted that the compressive strength of polymer and polymer concrete are related to the compressive modulus and splitting tensile strength while presenting a constitutive model for predicting the compressive stress-strain behavior [15]. Shao et al. [16] studied the mechanical properties of epoxy concrete by compressive, flexural, spilt, deflection, and strain experiments with added different percentages of fine, medium, and coarse rubber particles $(5 \%, 10 \%, 15 \%, 20 \%$, and $25 \%)$. They found that rubber in epoxy concrete helps in increasing the deformability while maintaining a sufficient interface resistance as a repair material.

Recently, epoxy resin concrete has gradually been introduced into bridge engineering as a repair material for bridge expansion joints due to the fragility and time consumption of normal strength concrete in the anchorage area of bridge expansion joint. The short curing time, high strength, and long life of epoxy resin concrete just make up for the shortcomings of traditional cement concrete.

However, the mechanical behavior of the bonded interface between the cement concrete and epoxy resin concrete is crucial in the system of concrete enhancement and repair [17].

Nevertheless, research about epoxy resin concrete needs further study because some weaknesses still need to be improved and optimized [16]. Ample research showed one of the crucial issues about the application of epoxy resin concrete which is the interface separation resulting from the distinct characteristics of epoxy-based and cement-based materials in collaboration and even the problems with stress concentration and premature destruction [17-22].

Numerous researches have been conducted in the bonding performance between two different materials. The most common interface bonding research is about the bonding between different aged concretes, which is a crucial influence for a reliable transmission of loads between the fresh and old concrete layers and the activation of repair and restoration materials in existing structures [23-25]. The mechanical characteristics of the concrete-to-concrete interface mainly depend on the roughness of surface, the normal stress at the interface, the differential rigidity, and the distinctive shrinkage between two concrete layers [26]. Cristina Zanotti et al. [23] investigated interfacial bonding properties between various aged concrete layers at two separate laboratories in Canada and Austria. The results indicated that shear bonding strength of push-out test was 5-10 times lower than that of slant shear test. This experimental finding was mostly attributed to the notable friction and interlocking impacts in the slant shear test and the slight bending induced by the small eccentricities in the push-out test. Moreover, the effect of fibers on bonding relies on stress conditions, fiber characteristics, material features, roughness of the interface, and direction of casting. Ceia et al. [27] studied bond strength of the interface between recycled aggregates concrete (RAC) and natural aggregates concrete (NAC) by slant shear test. They found that the design expression proposed by Santos and Julio [28] contributes to an upper interface shear strength assessment and cannot be applied to the recycled aggregates concrete (RAC) overlay. Ceia et al. reported that the codes provide more conservative values for all kinds of tested concrete, including RAC100 which has low concrete strengths.

Likewise, the research on interfacial bond properties between concrete layers has also focused on the ultra-highperformance concrete (UHPC) to cement concrete interface in the last decades. Most scholars' research is investigating the bonding strength between UHPC and cement concrete by various tests, including direct tensile test, splitting tensile test, push-out test, bi-surface shear test, and slant shear test $[29,30]$. Further researches mainly focus on the study of sensitive parameters, which affect the interface bonding strength [31-35]. Semendary and Svecova [36] examined five factors that affect the interfacial bonding strength between precast concrete (normal strength concrete and high strength concrete) and ultra-high-performance concrete casted in place by direct tension, push-off, bi-surface shear, and slant shear test. The conclusion was that the bonding strength of UHPC-NSC and UHPC-HSC had significant increase in the early UHPC age (3 days to 7 days) by $37.4 \%$ and $11.5 \%$, respectively. The bonding strength of UHPCNSC was slightly higher than that of UHPC-NSC in the age of 7 days $(4.2 \%)$ and 28 days $(9.5 \%)$. Moreover, the surface pretreatment of the saturated surface dry (SSD) increased the bonding strength to varying degrees for direct tension, bi-surface shear, and slant shear test by $3 \%, 22.7 \%$, and $2.3 \%$, respectively. They calculated the cohesion and shear friction coefficients by Coulomb theory and linear fit and found that these coefficients exceed the values in several codes by $60 \%$ $100 \%$ and $40 \% \sim 108 \%$, respectively (ACI 318-14, AASHOT LRFD, and CEB-FIB). The slant shear, splitting tensile, and direct tensile tests were carried out by Yang Zhang and Ping Zhu et al. to investigate the interfacial bonding strength between the NSC substrate and UHPC layer [37]. Their research covered seven influencing factors: the surface roughness, UHPC age, moisture degree, UHPC curing condition, NSC strength, bonding agent, and expansive agent. The results of these tests showed that the UHPC-NSC composite samples produce higher bonding strength compared to the NSC-NSC samples with the highest values exceeding $88.8 \%, 47.8 \%$, and $20.7 \%$ for slant shear test, splitting tensile test, and direct tensile test, respectively. They proposed that the main factors that affect the interface bond strength between the NSC substrate and UHPC overlay the most were the roughness of surface and the NSC substrate moisture degree, as well as the NSC strength.

Although numerous studies have been performed on the interfacial properties between various materials and cementbased materials, very few experimental information and evaluation methods are available for the behavior of bonding in the NSC-ERC composite specimens. In particular, the lack 
of a uniform mix ratio for epoxy resin concrete makes it difficult to predict the interfacial bonding strength between ERC and NSC.

The primarily goal of this paper is to estimate the interfacial bonding performances between this new type epoxy resin concrete and NSC substrate systematically by applying direct tensile, push-out, and slant shear tests. Particular concerns and discussion are concentrated on investigating the bonding strength and analyzing the failure modes and failure processes; and the experimental feasibility of special sizes and structure specimens was also verified. Finally, the cohesion and friction coefficients, which is used to calculate the minimum interfacial bond resistance of ERC-NSC, were calculated inversely in accordance with the outcome acquired from the corresponding direct tensile and slant shear tests. The consequence should attract the attention of the design and construction engineers concerned about assessing the bonding performance of ERC-NSC composite structure.

\section{Experimental Program}

2.1. Materials. In this experimental program, the normal strength concrete (NSC) of Grade-50 was selected as the concrete substrate as it is usually used in the bridge deck manufacture. The epoxy resin concrete (ERC) was used as a packing material for bridge expansion device due to its fast curing, fast growth of early strength, and good performance in elastic deformation. The NSC used for testing contains Portland cement (42.5 R), natural river sand, water reducer, and coarse aggregates composed of crushed stone with a particle size of $5-31.5 \mathrm{~mm}$. The NSC mix ratio used in this paper refers to the past experience of the Bridge Structural Engineering Safety Technology Laboratory of Chang'an University. The laboratory keeps various grades of cement and concrete mix ratios for students to use. In addition, $150 \mathrm{~mm}$ concrete cube specimens subjected to compressive tests verify the concrete strength. As presented in Table 1, the compressive strength of concrete used in this experiment is about $50 \mathrm{MPa}$, which can reach the requirements of C50 concrete. The composition of the new epoxy resin concrete is as follows: epoxy resin is used as the base material, combined with a certain proportion of curing agent and filler as an adhesive and sand and stone as aggregate. The epoxy concrete mix ratio used in this experiment was developed by Chengdu Datong Road Bridge Machinery Company Limited; and the material properties of this epoxy resin concrete are tested in the structural laboratory at Chang'an University.

The mix proportions of NSC and ERC are shown in Table 2.

The material characteristics of NSC were obtained by the experiment method specified in JTG E30-2005 [7]. The cubes with diameters of $150 \times 150 \times 150 \mathrm{~mm}^{3}$ were produced and tested for compressive strength and cube splitting tensile test, whereas the cylinders with dimensions of $150 \times 150 \times 300 \mathrm{~mm}^{3}$ were prepared to investigate the elastic moduli. The NSC samples were cured at a normal temperature and humidity for 28 days and their compressive strength and elastic moduli were tested.
TABLE 1: Overview of material characteristics.

\begin{tabular}{lcccc}
\hline Material & $f_{c}(\mathrm{MPa})$ & $E(\mathrm{GPa})$ & $f_{t s}(\mathrm{MPa})$ & $f_{t}(\mathrm{MPa})$ \\
\hline NSC $(28 \mathrm{~d})$ & 50.3 & 37.1 & 4.5 & - \\
ERC $(7 \mathrm{~d})$ & 17.3 & 1.2 & - & 3.92 \\
ERC $(28 \mathrm{~d})$ & 49.0 & 7.7 & - & 4.64 \\
\hline
\end{tabular}

For the mechanical characteristic tests of epoxy resin concrete (ERC), the specimens utilized for the compressive strengths were cube samples of $100 \times 100 \times 100 \mathrm{~mm}^{3}$ and for the elastic moduli they were prism samples of $40 \times 40 \times 160 \mathrm{~mm}^{3}$. Additionally, the dumbbell-shaped samples with a rectangular section of $25 \times 25 \mathrm{~mm}^{2}$ in the middle part were used for tensile test.

Table 1 displays an overview of the NSC and ERC mechanical characteristics. During the curing of epoxy resin concrete, we tested the elastic modulus for 7 days and 28 days. In the early tests of epoxy resin concrete, the amount of deformation was relatively large, and bulging was the main failure phenomenon of the specimens, and its elastic modulus was closer to that of asphalt concrete $(0.8 \sim 1.6 \mathrm{GPa})$. As the age increases, the amount of deformation during the test is relatively small. The test failure phenomenon is mainly cracking which is closer to cement concrete; and its elastic modulus increases accordingly. On the 28th day, the elastic modulus of epoxy concrete is only about one-fifth of that of cement concrete.

2.2. Preparation of the Specimens. The NSC-ERC bonding behavior was tested under direct tension, push-out, and slant shear with special sizes; the details of three kinds of specimens are shown in Table 3 and Figure 1.

For the direct tensile test, the specimen consists of two rectangular NSC with a size of $300 \times 300 \times 150 \mathrm{~mm}$ on both sides and a rectangular ERC with size of $150 \times 300 \times 100 \mathrm{~mm}$ in the middle. To prepare specimens for direct tension, NSC with dimensions of $300 \mathrm{~mm}$ by $300 \mathrm{~mm}$ and $150 \mathrm{~mm}$ thickness were cast in $150 \mathrm{~mm}$ deep formwork. The concrete slabs were demolded after $24 \mathrm{~h}$ and kept in the maintenance room for 28 days under room conditions with temperatures of $23^{\circ} \mathrm{C} \pm 2^{\circ} \mathrm{C}$ and $50 \% \pm 10 \%$ relative humidity (RH). Before pouring the ERC material, the NSC surface was power chiseled to expose aggregate and cleaned the cement mortar of surface. Then the NSC was fixedly placed in the mold and then ERC was cast. All specimens have finally been cured in the same curing conditions as described above.

The following description relates to the preparation of specimens in push-out test. The push-out specimens were prepared by using two rectangular NSC with a size of $300 \times 300 \times 150 \mathrm{~mm}$ on both sides and a rectangular ERC with size of $300 \times 300 \times 100 \mathrm{~mm}$ in the middle. After casting the NSC slab, the specimens were kept in the cure room for 28 days under room conditions. The process of casting ERC is similar to that of direct tensile test. It should be noted that, in order to facilitate loading, the ERC slab is $50 \mathrm{~mm}$ higher than the NSC slab on both sides. In the testing setup, lateral supports were introduced to restrain the lateral displacement of the concrete slabs on both sides. During the loading 
TABLE 2: Mix proportions of NSC and ERC.

\begin{tabular}{lccc}
\hline Materials & Constituents & Amount $\left(\mathrm{kg} / \mathrm{m}^{3}\right)$ & Appearance \\
\hline & Portland cement $(42.5 \mathrm{R})$ & 575 & Gray powder \\
& River sand & 705 & Yellow particle \\
Grade-50 & Coarse aggregate $(10-31.5 \mathrm{~mm})$ & 846 & - \\
NSC & Coarse aggregate $(5-10 \mathrm{~mm})$ & 210.15 & - \\
& Water & 157 & Colorless liquid \\
& Water reducer & 4.8 & Light yellow liquid \\
& W/P ratio & 0.27 & - \\
ERC & Epoxy resin & 450 & Black liquid \\
& Curing agent & 74 & Light yellow liquid \\
& Aggregate & 1950 & Light colored particles \\
\hline
\end{tabular}

TABLE 3: Details of three kinds of specimens.

\begin{tabular}{lclc}
\hline Specimen type & NSC shape and size $(\mathrm{mm})$ & ERC shape and size $(\mathrm{mm})$ & Interface $^{\text {area }}\left(\mathrm{mm}{ }^{2}\right)$ \\
\hline Direct tension & Rectangular $300 \times 300 \times 150$ & Rectangular $150 \times 300 \times 100$ & $150 \times 300$ \\
Push-out & Rectangular $300 \times 300 \times 150$ & Rectangular $300 \times 300 \times 100$ & $250 \times 300$ \\
Slant shear & Trapezoidal $(50+350) \times 300 \times 150$ & Rectangular $300 \times 150 \times 100$ & $300 \times 150$ \\
\hline
\end{tabular}

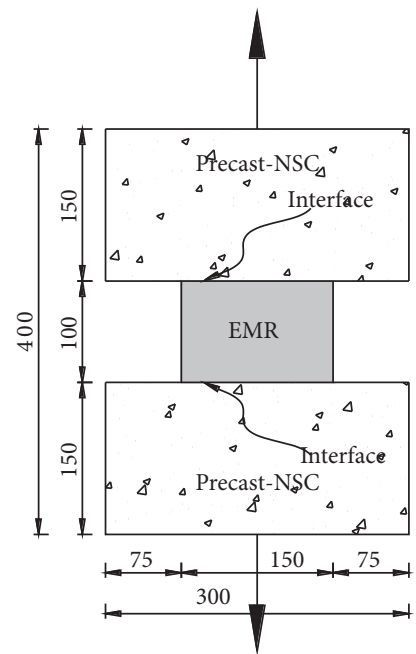

(a)

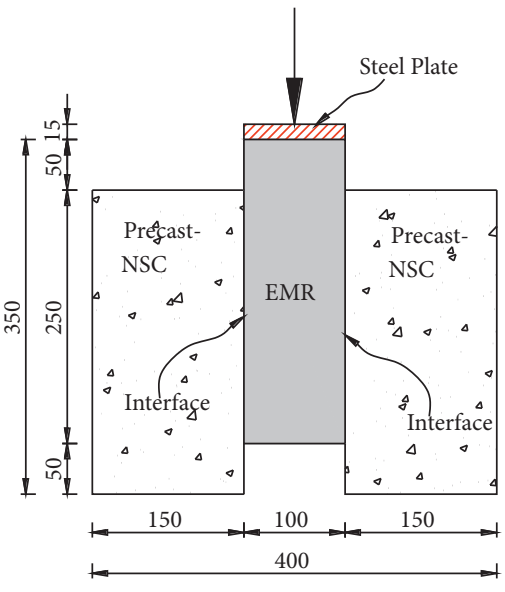

(b)

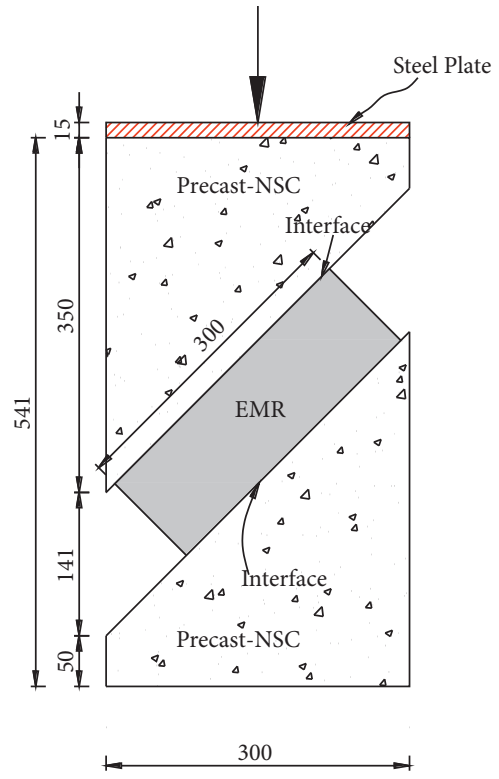

(c)

Figure 1: Specimen details for three tests: (a) direct tension; (b) push-out; (c) slant shear (all dimensions in mm).

phase, the lateral displacement of the concrete slab will cause a lateral tensile force on the interface, which will result in the interface of the composite specimen to bear no more pure shearing force and lateral tension. In this state of stress, the composite specimen will test lower interfacial shear strength.

The prismatic specimens used for slant shear test consist of three parts: two trapezoidal concrete slabs with a dimension of $(50+350) \times 300 \times 150 \mathrm{~mm}$ and an epoxy resin concrete block with a size of $300 \times 150 \times 100 \mathrm{~mm}$ in the middle. In order to generate shear stress, the interface between NSC and ERC forms a $45^{\circ}$ interface angle from vertical. Carbonell Muñoz et al. [32] have examined the bonding capacity between NSC (dry and saturated dry surface dry) and UHPC by slant shear test with $55^{\circ}, 60^{\circ}$, and $75^{\circ}$; the findings show that the bonding strength was significantly affected by the interface angle. When the interface angle is $45^{\circ}$, the distribution of pressure and shear force is one to one. When it is less than $45^{\circ}$, the shear stress is dominant, and when it is greater than $45^{\circ}$, the compressive stress is greater. In this paper, specimens with $45^{\circ}$ inclined plane angle are used for the first time to investigate the interfacial bonding capacity between NSC and ERC under a combined stress whose compressive stress and shear stress are equal and the failure mode of these specimens is observed. Based on the results of this experiment, a research with the interface angle as a variable will be conducted to 
obtain the interfacial bonding properties between NSC and ERC under different interface angles in the further study. The samples casting was divided into two steps, with NSC parts of the specimen cast firstly, while utilizing a board as mold on the inclined surface. After $24 \mathrm{~h}$, the NSC specimen was demolded and chiseled to expose the surface aggregate. These samples were kept in the curing room for 28 days. In the conventional slant shear test, the specimen is a prism with a trapezoidal substrate material on one side and a trapezoidal overlay material on the other side. However, since the smaller elastic modulus of ERC in early age, it is possible that the specimen will be unloaded due to excessive deformation of the ERC before the load reaches the failure load. Thus, in this experiment, the specimens were specifically designed to two concrete slabs in upper and lower sides to obtain the failure load.

In this paper, the test setups for direct tensile, push-out, and slant shear tests were different from all the standards and codes, such as ASTM and BS EN. The most important adjustment is that we specially designed specimens' size for increasing the interfaces area to adapt the $1000 \mathrm{kN}$ test machine. Only in this way can the testing machine be within the effective working range to obtain more accurate experimental results.

2.3. Testing Procedure. The test methods for the three tests are briefly described in this section. Among the various experiments to evaluate the bonding strength between two distinct materials, the tensile test is the most direct and simple test. In fact, many codes of practice recommend direct tensile test for bond performance assessment at the construction site. However, the direct tension test was being considered to rather underestimate bonding capacity. As shown in Figure 2(a), the specimen was fixed by two special steel clamps to connect to the tensile testing machine. The testing protocol used a constant displacement rate of $2.0 \mathrm{~mm} / \mathrm{min}$ until failure. The direct tensile bonding strength $\left(f_{t}\right)$ of the ERC-NSC interface was estimated as

$$
f_{t}=\frac{P}{A_{t}},
$$

where $P$ is maximum applied load; $A_{t}$ is the area of the bonding plane.

Unlike the slant shear test, there is no compressive stress applied in the interface of push-out test. The bonding strength in the push-out test is dramatically influenced by interfacial friction and interlocking force. A steel plate at the top of the specimens served for load distribution. The push-out specimens were loaded with compressive forces at the top of the steel plate, and the adopted displacement rate was $1 \mathrm{~mm} / \mathrm{min}$ to $2 \mathrm{~mm} /$ $\min$. Figure 2(b) displays the test setup with a dashed line in the interface. Equation (2) was applied to obtain the pure shear bonding strength $(\tau)$ between ERC and NSC.

$$
\tau=\frac{P}{2 A_{\tau}},
$$

where $P$ is maximum applied load; $A_{\tau}$ is the area of the bonding plane.
The prisms utilized in slant shear test were loaded with a universal pressure at a $2.0 \mathrm{~mm} / \mathrm{min}$ displacement rate. Similar to the push-out test, the force was distributed by a steel plate on the top of the specimens. This compression generated shear stresses and the normal stressed perpendicular to the inclined surface. The following equation is used to calculate the shear and normal stresses at the interface of slant shear specimens:

$$
\begin{gathered}
\tau_{n}=\frac{P}{A_{s}} \sin \alpha, \\
\sigma_{n}=\frac{P}{A_{s}} \cos \alpha,
\end{gathered}
$$

where $\tau_{n}$ and $\sigma_{n}$ are shear and normal stresses acting on the bond plane, respectively; $P$ is maximum applied load; $A_{s}$ is the area of the bonding plane; and $\alpha$ is bond plane inclination with respect to the vertical.

\section{Results and Discussion}

3.1. Failure Modes. The literature shows the three failure types: pure interface failure (I), partial interface failure (II), and complete NSC substrate or ERC overlay failure (III) [37]. The judgment of the failure modes is mainly based on the features and location of the failure plane. The pure interface failure means the failure occurred at the bond interface, along the interface with simultaneous and smooth concrete failure neighboring the interface. No cracks and fracture could be detected in both the NSC substrate and the ERC overlay. The second type partial interface failure occurs in the transition zone and partial concrete fails adjacent to the interface. In the failure characteristics of the second failure mode, it can generally be observed that partial thin layer of NSC substrate materials is attached to the ERC surface. The last one is complete concrete failure with crushing of the weakest concrete, which occurred in NSC substrate or ERC overlay with intact NSC-ERC interface. Normally, the test results obtained from failure modes mode I or mode II represent the actual bonding strength of NSCERC interface, but the result of failure mode III is only the lower limit value of the bonding strength.

3.2. Test Results. The ACI 546.3R-06 Concrete Repair Guide [38] provides the typical test values of concrete replacement materials (mainly including various Portland or blended cement-based mortar and concrete, silica-fume mortar and concrete, polymer-cement mortar and concrete, and polymer-based mortar and concrete) for slant shear bond and direct tensile bond and direct tensile bond, which are summarized in Table 4. In this paper, the epoxy resin concrete was used for repairing material which means its quality of bonding strength can be evaluated with the interfacial bond quality specified in the guide and assessment criterion.

Table 5 presents the experimental results from the direct tensile, push-out, and slant shear tests with NSC substrate with 8 months (aged concrete) and ERC overlay with 7 days, 


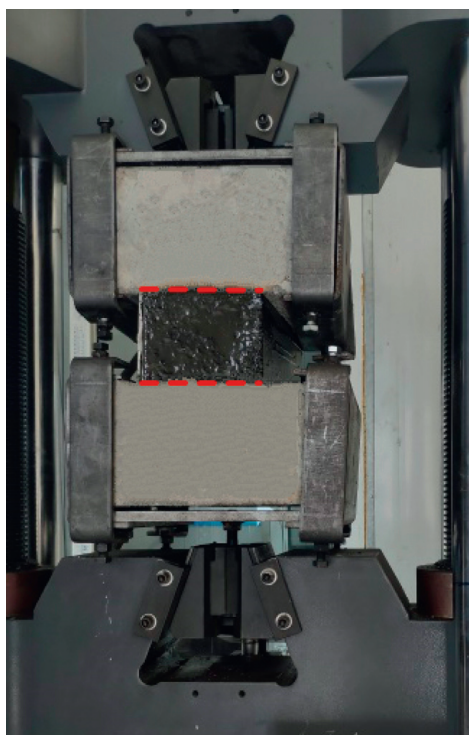

(a)

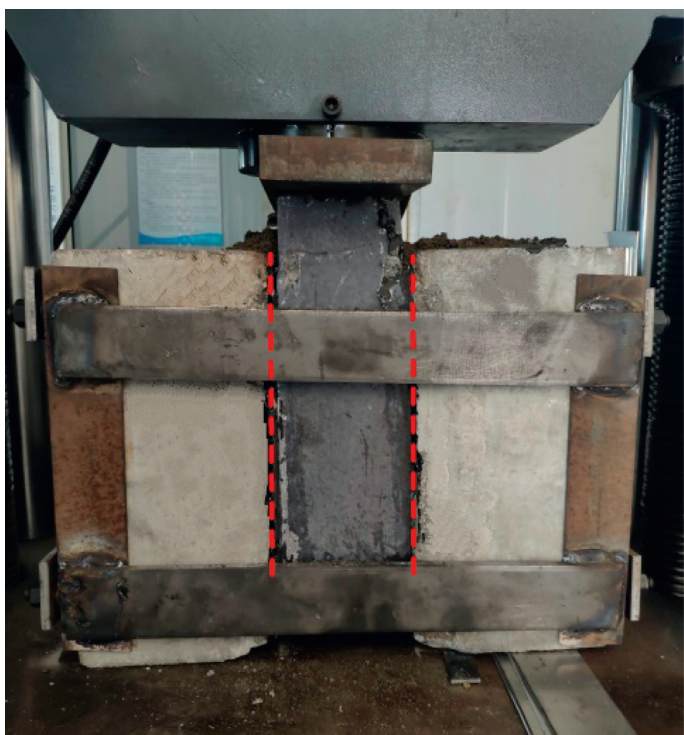

(b)

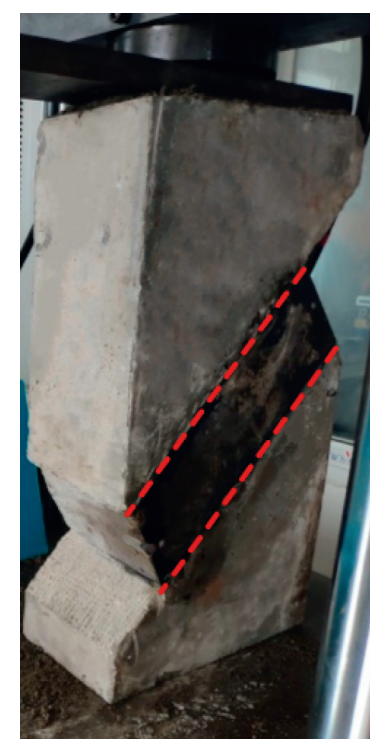

(c)

Figure 2: Test specimens. (a) Direct tension. (b) Push-out. (c) Slant shear.

TABLE 4: Summary of available test methods and test values for concrete replacement materials.

\begin{tabular}{lcccc}
\hline \multirow{2}{*}{ Description } & \multicolumn{2}{c}{ Typical bond strength value (MPa) } & Test method \\
& At the 1st day & At the 7th day & At the 28th day & ASTM C 882, ASTM C 1042 \\
Slant shear bond & $2.8-6.9$ & $6.9-12$ & $14-21$ & ACI 503R, ASTM C 1404/C 1404M, CSA A23.2-6B, ASTM C 1583, \\
$\begin{array}{l}\text { Direct tensile } \\
\text { bond }\end{array}$ & $0.48-1.0$ & $1.0-1.7$ & $1.7-2.1$ & ICRI 03739 \\
Direct shear bond & $1.0-2.1$ & $2.1-2.8$ & $2.8-4.1$ & MDOT \\
\hline
\end{tabular}

including mean bonding strengths $\left(f_{t}, \tau_{n}\right.$, and $\left.\sigma_{n}\right)$, failure modes, standard deviation (SD), and coefficient of variation $(\mathrm{COV})$ of each test group. The results in Table 5 indicate that the bonding strengths of push-out test are higher than those of direct tensile test, while the mean value of the former is about 2 times that of the latter. Among the three different tests, the bonding strengths from slant shear test are considerably superior to the other two test findings. The experimental results show that the slant shear bonding strength between epoxy resin concrete (ERC) and normal strength concrete (NSC) ranges from 3.19 to $8.33 \mathrm{MPa}$, the direct tensile strength ranges from 0.72 to $1.0 \mathrm{MPa}$, and the direct shear strength ranges from 1.71 to $1.89 \mathrm{MPa}$. Compared with the 7 days' bonding strength range in the above evaluation criterion, the bonding strengths of the ERC and NSC are lower, only reaching the bonding strength at 1st day. It can be seen that, in these experiments, the bonding strengths of epoxy resin concrete (ERC) and normal strength concrete (NSC) do not reach the value recommended in codes. Therefore, in further study, the factors that affect the bonding strength of the two materials can be considered to improve the bonding strength so that it can be better used as a filler material for practical engineering. The test results of the three tests, test phenomena, and failure modes will be analyzed in detail in the next section.
3.2.1. Bonding Strength of Direct Tensile Test. It can be seen from Table 5 that the minimum and maximum tensile bonding strengths ranged between $0.72 \mathrm{MPa}$ and $1.00 \mathrm{MPa}$ at 7 th day. The mean tensile bonding strength is $0.88 \mathrm{MPa}$ and the standard deviation is 0.01 . Additionally, the coefficient of variations (COV) of the tensile bonding strength of NSC-ERC interface is $1.55 \%$, and the low COV can be considered to justify the reliability of the tests. As shown in Figure 3, the load-displacement curves of the three direct tensile tests have the same trend. In the initial stage, with the increase of displacement, the force value rises slowly. There was a slight noise in the test phase, which can be considered as appearance of micro cracks or partial bonding failure. In the middle stage, the force value increases sharply with the displacement and reaches the peak value. Then, accompanied by a crisp sound, the load drops suddenly, indicating that the composite specimen was broken and the NSC and ERC have been separated. The test curve is consistent with the experimental phenomenon.

After the direct tensile test, from the observed characteristics and location of the failure plane, it can be determined that the failure mode is type II. As shown in Figure 4, all the three composite specimens are the concrete failure in the upper NSC. The aggregate in the NSC concrete was exposed, whereas partial concrete mortar and small 
TABLE 5: Experimental results in the direct tensile, push-out, and slant shear tests.

\begin{tabular}{|c|c|c|c|c|c|c|c|}
\hline Samples & & Failure mode & $f_{t}(\mathrm{MPa})$ & $\tau(\mathrm{MPa})$ & Mean (MPa) & $\mathrm{SD}(\mathrm{MPa})$ & COV (\%) \\
\hline \multirow{3}{*}{ Direct tensile test } & 1 & II & 0.72 & & \multirow{3}{*}{0.88} & \multirow{3}{*}{0.01} & \multirow{3}{*}{1.55} \\
\hline & 2 & II & 0.91 & & & & \\
\hline & 3 & II & 1.00 & & & & \\
\hline \multirow{3}{*}{ Push-out test } & 1 & II & & 1.89 & \multirow{3}{*}{1.82} & \multirow{3}{*}{0.01} & \multirow{3}{*}{0.45} \\
\hline & 2 & II & & 1.71 & & & \\
\hline & 3 & II & & 1.86 & & & \\
\hline \multirow{3}{*}{ Slant shear test } & 1 & III & & 4.09 & \multirow{3}{*}{5.20} & \multirow{3}{*}{5.02} & \multirow{3}{*}{96.53} \\
\hline & 2 & II & & 3.19 & & & \\
\hline & 3 & III & & 8.33 & & & \\
\hline
\end{tabular}
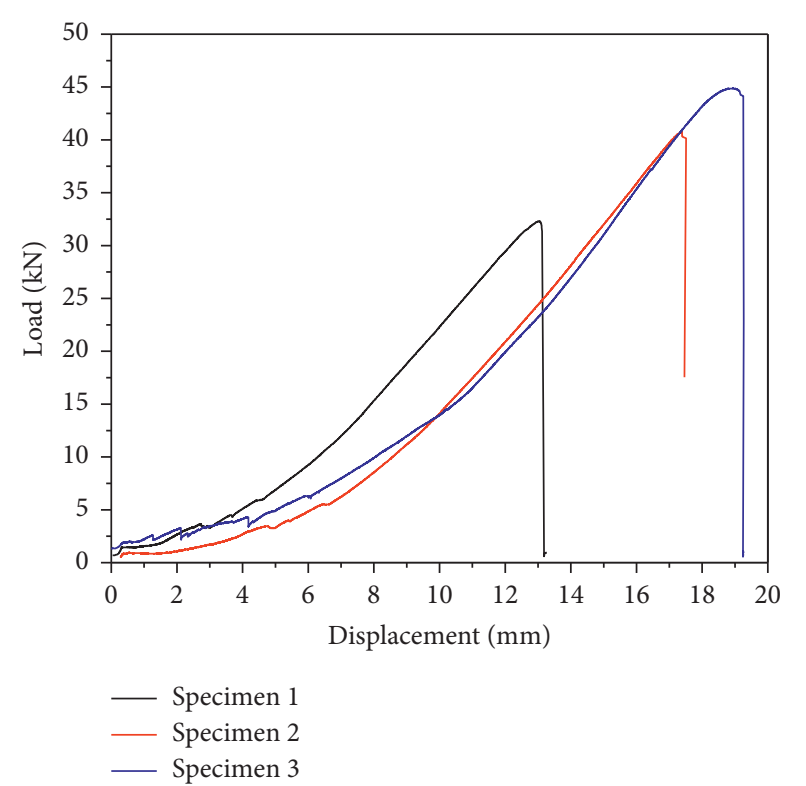

Figure 3: The direct tensile test specimen load-displacement curves.

aggregate were attached to the ERC surface. The bonding capabilities obtained from direct tensile test are not the real performance of the interface bonding but the lower limits of the true bonding strength value.

3.2.2. Bonding Strength of Push-Out Test. Shear bonding stresses for push-out tests are shown in Table 5. The minimum and maximum shear bonding strengths were between 1.71 $\mathrm{MPa}$ and $1.89 \mathrm{MPa}$ with an average value of $1.82 \mathrm{MPa}$ and a standard deviation of $0.01 \mathrm{MPa}$. The coefficient of variation is $0.34 \%$, which indicates that the test results are reliable. As shown in Figure 5, for push-out tests, the test load-displacement curves first slowly go up followed by sharp ascent and eventually reduce abruptly after the peak. In the early stage of the test, it can be observed that there was small vertical displacement of the middle ERC block. In the later stage, there was a sudden and crisp sound, while the single-sided NSC block was separated from the ERC block.

Since the composite specimens were only damaged on one side, continued load until the shear surface on the other side failed. Two secondary loading methods were adopted in the experiment. For specimen 1, the first load was removed and then reloaded. Similar to the first load-displacement curve, that of secondary loading also rises temporarily and gently, followed by a longer period of sharp rising, and reaches the peak load. Finally, the second shear surface of the composite specimen failed, while the curve dropped sharply. Unlike specimen 1, specimen 2 was loaded continuously. When the first load peak is reached for the first time, the onesided shear surface is damaged. After that, the test curve drops to a lower value and then reloads to the second peak. At the same time, the other side's shear surface of specimen 2 failed.

The failure surfaces of push-out test specimens are shown in Figure 6. The aggregate of the shear surface in the NSC substrate was exposed in a large area, while the concrete mortar and small aggregate were attached to the ERC overlay surface. It can be judged that the specimens of push-out test failed with mode II. For push-out test, the shear bonding strengths represent the pure shear stress in the interface between NSC and ERC. However, tensile stresses act on the interface of NSC to ERC, which is subjected to slight bending moment effect. Thus, the bonding values obtained from push-out test were rather low because of minor eccentricities that are inevitable between load introduction and support points.

3.2.3. Bonding Strength of Slant Shear Test. In the slant shear tests, as expected, the bonding strengths from slant shear were higher than those of direct tensile and push-out tests due to the larger interlocking and frictional forces generated by the compression. The lowest and highest shear bonding strengths were between $3.19 \mathrm{MPa}$ and $8.33 \mathrm{MPa}$ with a high coefficient of variation of $96.53 \%$. The results demonstrated that the average value is not conserved sufficiently to evaluate the real shear bonding capability. The load-displacement curves of slant shear test are shown in Figure 7.

As demonstrated in Figure 8, the findings of the slant shear test are more complicated and the failure mechanisms of the three samples are various. In Figure 7, the load-displacement curve of specimen 1 goes slowly at the beginning of the test, and the curve rises sharply in the middle of the test with the load rising quickly. During the experiment process, it can be observed that there were micro cracks in the ERC block which is in the middle of the composite sample. As the load increased, the crack width slowly increased. At the same time, the ERC block slowly moved upward and downward on the oblique shear surface. When the load reached the peak value, the load was 

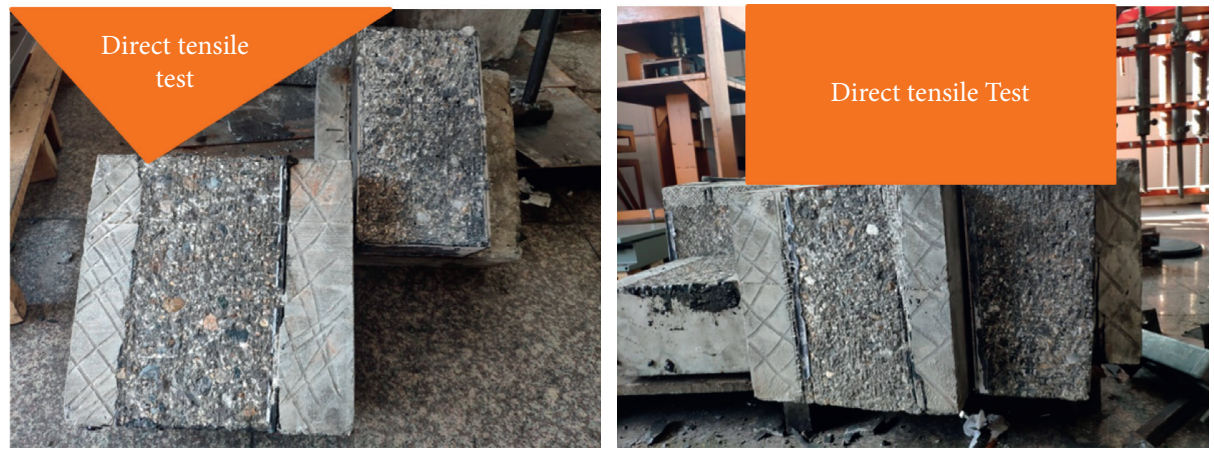

Figure 4: The failure mode of the direct tensile test specimen.

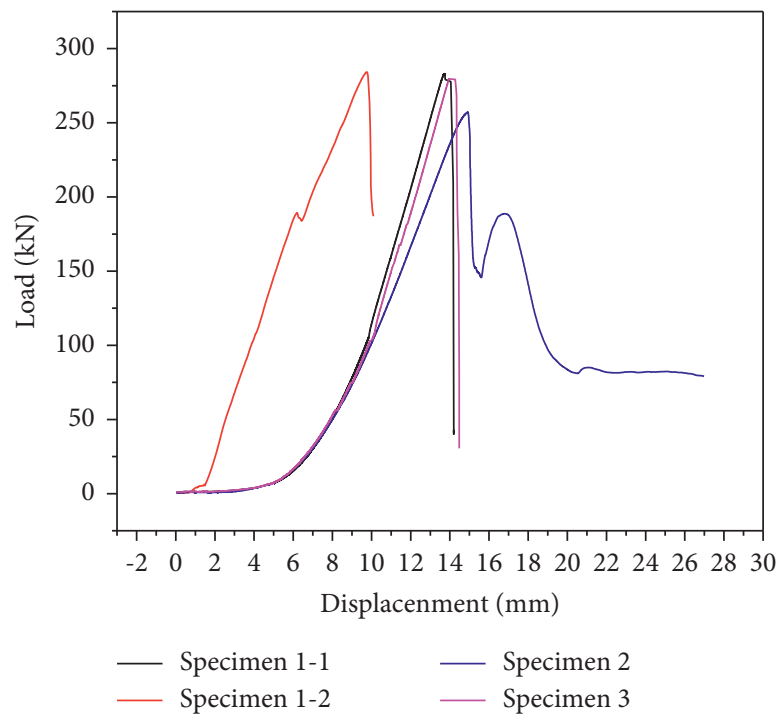

Figure 5: The push-out test specimen load-displacement curves. Note. Specimen 1-1 means the first load of specimen 1; specimen 1-2 means the second load of specimen 1 .
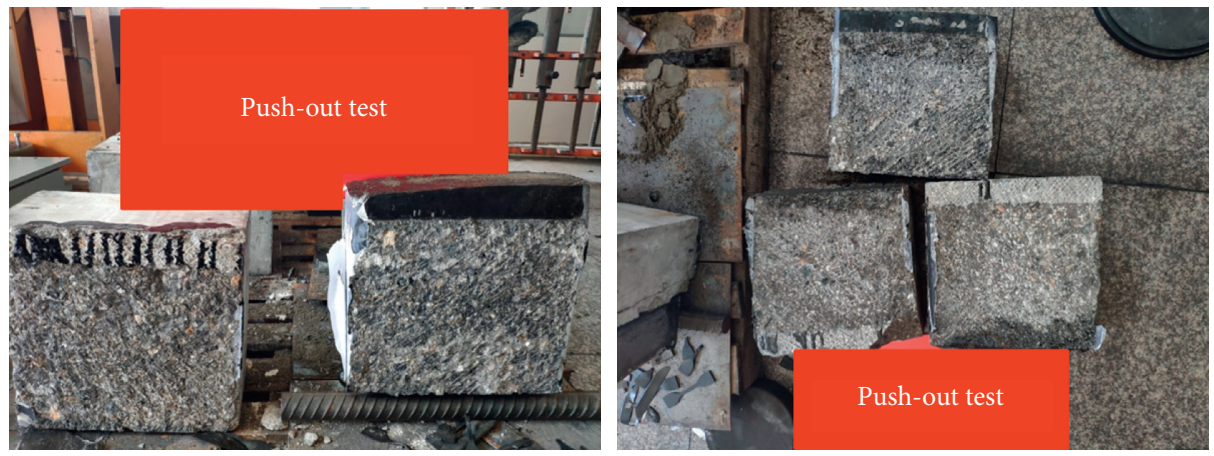

Figure 6: The failure mode of the push-out test specimen.

automatically unloaded and the test could not continue, but the specimen did not fail at bond interface. The damage characteristics on the two sides of specimen 1 are shown in Figure 9. There are two diagonal cracks on one side of the middle ERC block and three diagonal cracks on the other side. Thus, considering specimen 1 as oblique shear failure of ERC substrate, it can be judged as failure mode III.
The rising trend of the load-displacement curve of specimen 2 in the early stage is similar to that of specimen 1 , but the load in the middle and late stages rises significantly faster than that of specimen 1 . The ultimate peak value of specimen 2 is about $20 \%$ lower than that of specimen 1 , and the load was unloaded earlier than that of specimen 1 . During test loading, the micro cracks can be observed on the 


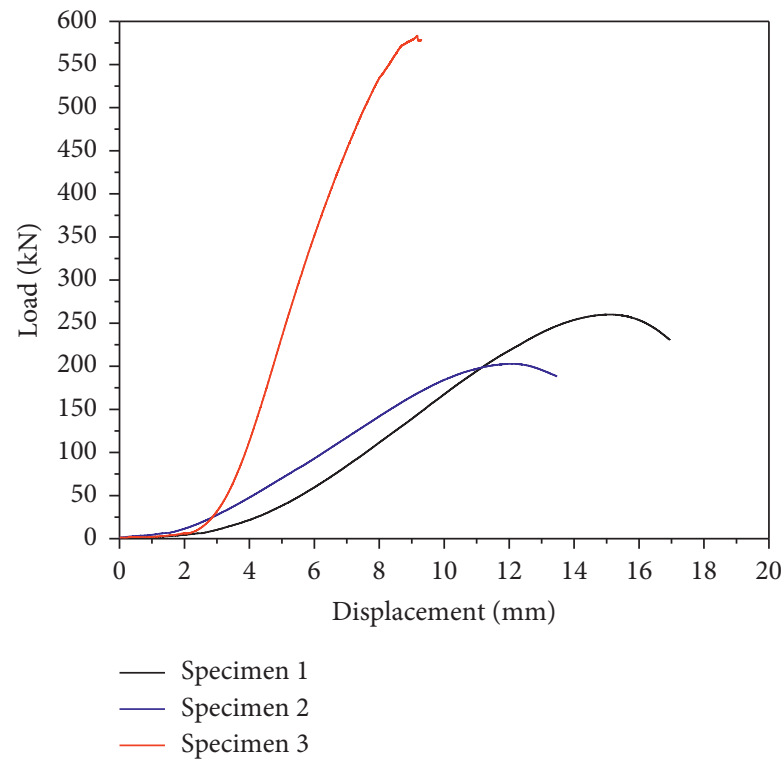

FIGURE 7: The slant shear test specimen load-displacement curves.

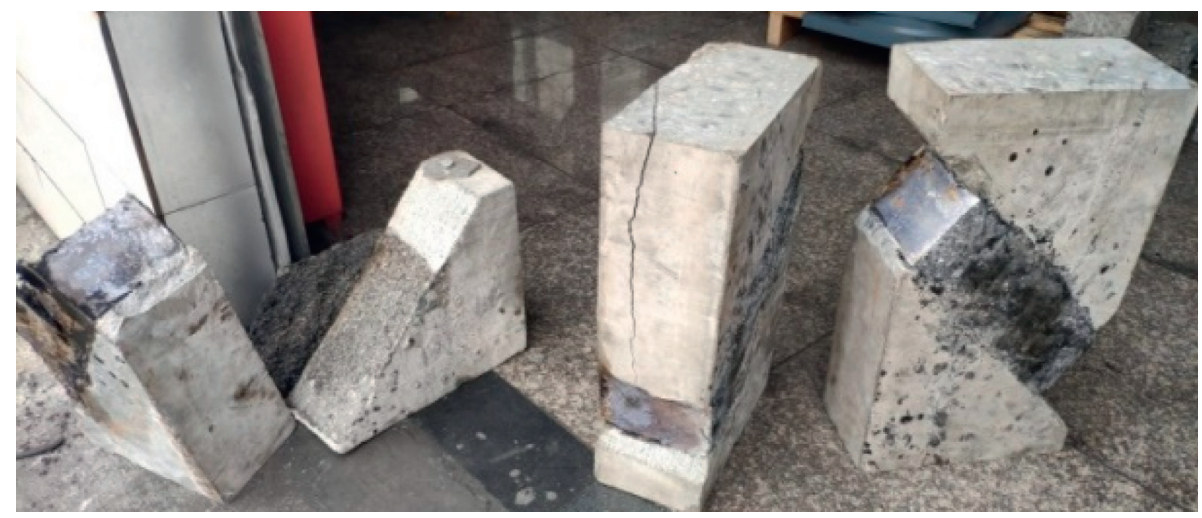

Figure 8: The failure mode of the slant shear test specimen.
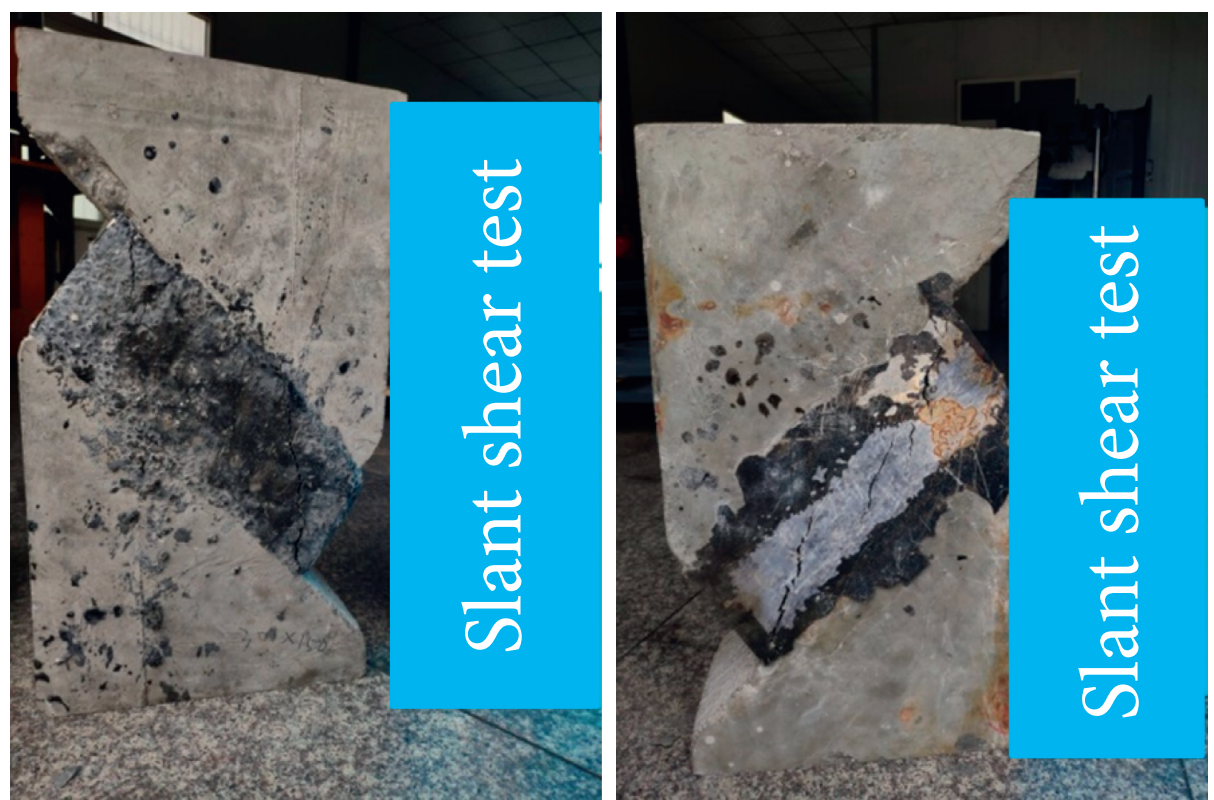

FIgURE 9: The failure mode of slant shear test specimen 1. 
interface of the upper NSC substrate and ERC overlay, and the diagonal crack occurred on the upper side of ERC block. As the load increased, the bonding interface of NSC and ERC gradually moved downward, while the diagonal cracks generated on the ERC spread slowly. When the load of specimen 2 reached the peak value, there was a through diagonal crack generated on the ERC overlay. Finally, the ERC block was cut from the NSC subgrade. The failure surface of specimen 2 is shown in Figure 10. Partial surface of ERC overlay was attached to the surface of NSC substrate and some fine aggregates of ERC were exposed, which can be judged as failure mode II.

The initial load-displacement curve of specimen 3 is relatively consistent with specimen 1 and specimen 2 , but, after a short and slow rise, the curve rises sharply and reaches the peak load quickly. At this time, the displacement value of specimen 3 is about half of that of specimen 1 at a peak load. At the same time, the load value has a downward trend, but the later unloading curve is not measured due to a through vertical crack that occurred on the upper concrete block and the experiment cannot continue. In the middle of the test, it can be observed that the middle ERC block was gradually pushed downward and upward; and diagonal cracks occurred on the ERC block and continued to expand. When the load reached $540 \mathrm{kN}$, the upper concrete block suddenly produced vertical cracks and the specimen was unloaded. However, at this time, the bonding surface of NSC and ERC was not completely destroyed. As shown in Figure 11, there is a wide diagonal crack on one side of the ERC overlay and the other side is intact. There is a small downward displacement of the middle ERC block. For NSC substrate, vertical cracks occurred on a corner of the upper concrete block. Thus, in this experiment, specimen 3 was judged as failure mode III.

From the test phenomena and test results during the test, when the angle of inclination is $45^{\circ}$, it is more difficult to fail in failure mode I or failure mode II, resulting in the inability to obtain the true interface bonding stress. However, the bonding strength was expected to be higher than the values measured because the ERC or NSC side failed instead of the interface. As Zanotti and Randl highlighted [23], the bonding strength is related to the slant angle, not the material characteristics; thus small slant angle should be utilized in this experimental program to induce interfacial failure.

From the first portion of the load-bearing curves, the larger displacement amount corresponds to the smaller load value. The phenomenon may be due to the fact that the early test machine does not reach the effective test range in the early stage, or the fine corner of specimens contacts the testing machine, or the void of the specimens is not compacted. The nonlinear curves of the first portion are the process of crushed corners or compacting void. In Figure 3, the nonlinear curves in the first portion of load-displacement curves are significant; and, with the increase of displacement, the load value is fluctuated up and down. This phenomenon considers the process of contact and tightening the specimen and fixture. For the curve for specimen 1-2 in Figure 5, the nonlinear curve of the first part is significantly short. It is considered that the factors of fine corners and void have been eliminated by the first loading.
In the further study, repeated preloading is considered to eliminate the effects of fine corners and voids of specimens, as well as clamps. At the same time, high-precision testing machines can be used to improve test results.

3.3. Determination of Cohesion and Shear Friction. Similar to the assessment technique on interfacial bonding strength of the NSC-NSC, the load transfer mechanism at concrete-epoxy resin concrete primarily relies on cohesion, friction, and even dowel action in certain design codes [28]. The cohesion is related to the roughness of surface and the tensile properties of concrete, while the friction is linked with roughness only. There is no shear reinforcement in specimens, so the shear strengthening effects should not be considered in this experiment. The interfacial bonding capacity can be simplified as

$$
\tau_{n}=c+\mu \sigma_{n}
$$

where $\tau_{n}$ is shear stress of the bond interface; $c$ is adhesive strength (the pure shear strength), $\sigma_{n}$ is compressive stress normal to the shear interface, $\mu=\tan (\varphi)$ is the coefficient of friction, and $\varphi$ is the internal friction angle.

In the AASHTO code, it recommends the values of coefficient $c$ and friction $\mu$ for the different roughness of NSC to NSC interface. For roughness surface, it specified 1.65 $\mathrm{MPa}$ and 1.0 , while $0.5 \mathrm{MPa}$ and 0.6 were specified for the smooth surface correspondingly. If only tensile stress acts on the interface, then the compressive stress normal to the shear interface is zero, and the tensile bonding strength of the failing plane is indicated by equation (4). Similarly, for the UHPC-NSC interface, the values of coefficient $c$ and friction $\mu$ can be derived as $2.2 \mathrm{MPa}$ and 1.37 for the roughness interface and $2.18 \mathrm{MPa}$ and 1.2 for smooth interface, suggested by Yang Zhang and others [37].

As shown in Table 6, the obtained value of bonding strength under pure shear and slant shear stress can determine the coefficient of friction and the results. Compared with the values for the rough interface of NSC to NSC provided in the AASHTO, the findings in Table 6 show that the friction coefficient $(\mu)$ for the ERC-NSC interface in this study is slightly lower than the reference value and the cohesion (c) is slightly greater [39]. The values of $c$ and $\mu$ for the ERC-NSC interface are substantially less than those of the UHPC-NSC interface recommended by Yang Zhang and others [37].

The results demonstrated that the minimum cohesion and the inverse computed friction coefficients for the ERCNSC interface were $1.71 \mathrm{MPa}$ and 0.46 , while the average values were $1.82 \mathrm{MPa}$ and 0.65 . Based on the minimal results from Table 6 , the suggested values of $c$ and the $\mu$ for this type of ERC-NSC interface can be derived as $1.71 \mathrm{MPa}$ and 0.46 . It is worth noting that, despite the scant specimens in this research, the consequences are still valuable to determine the cohesion and friction coefficient for calculating the interfacial bonding capability by the method in AASHTO. However, the bonding properties of the ERC-NSC interfaces vary considerably due to many variables, such as substrate roughness, moisture, the curing times and condition, and 

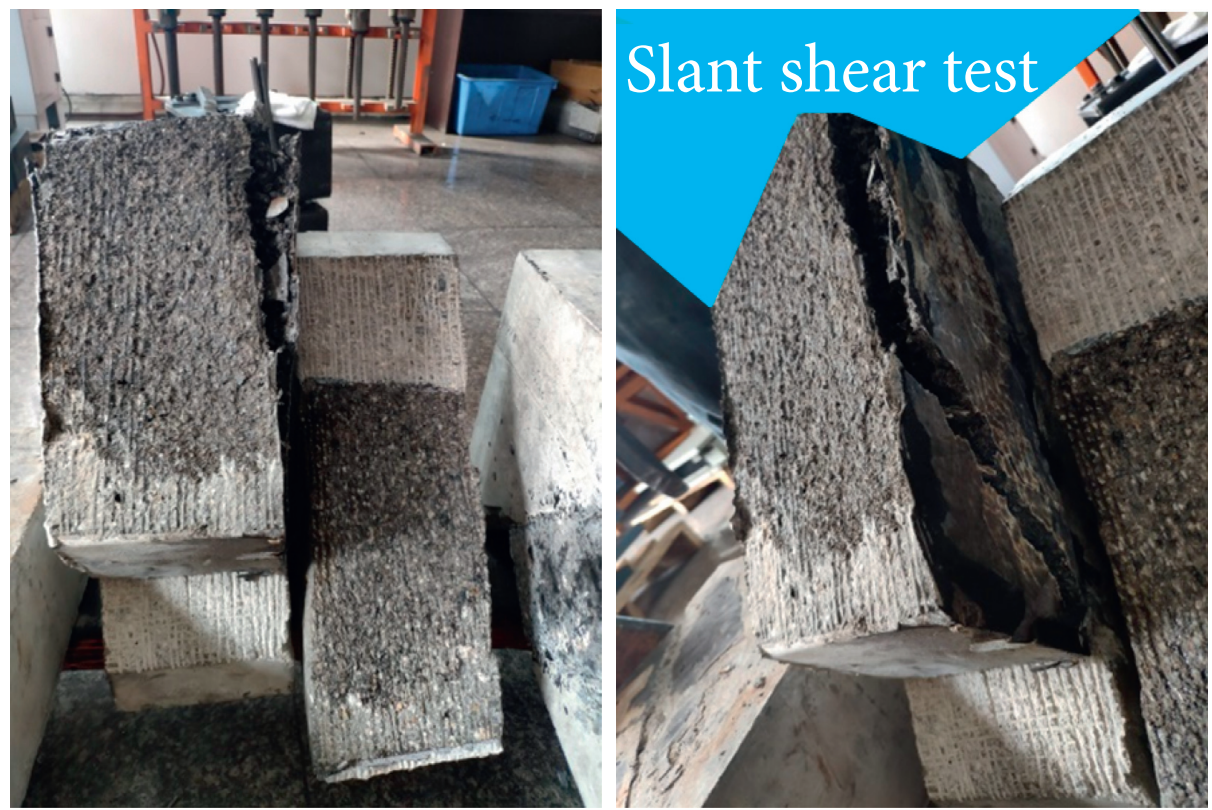

FIgUre 10: The failure mode of slant shear test specimen 2.
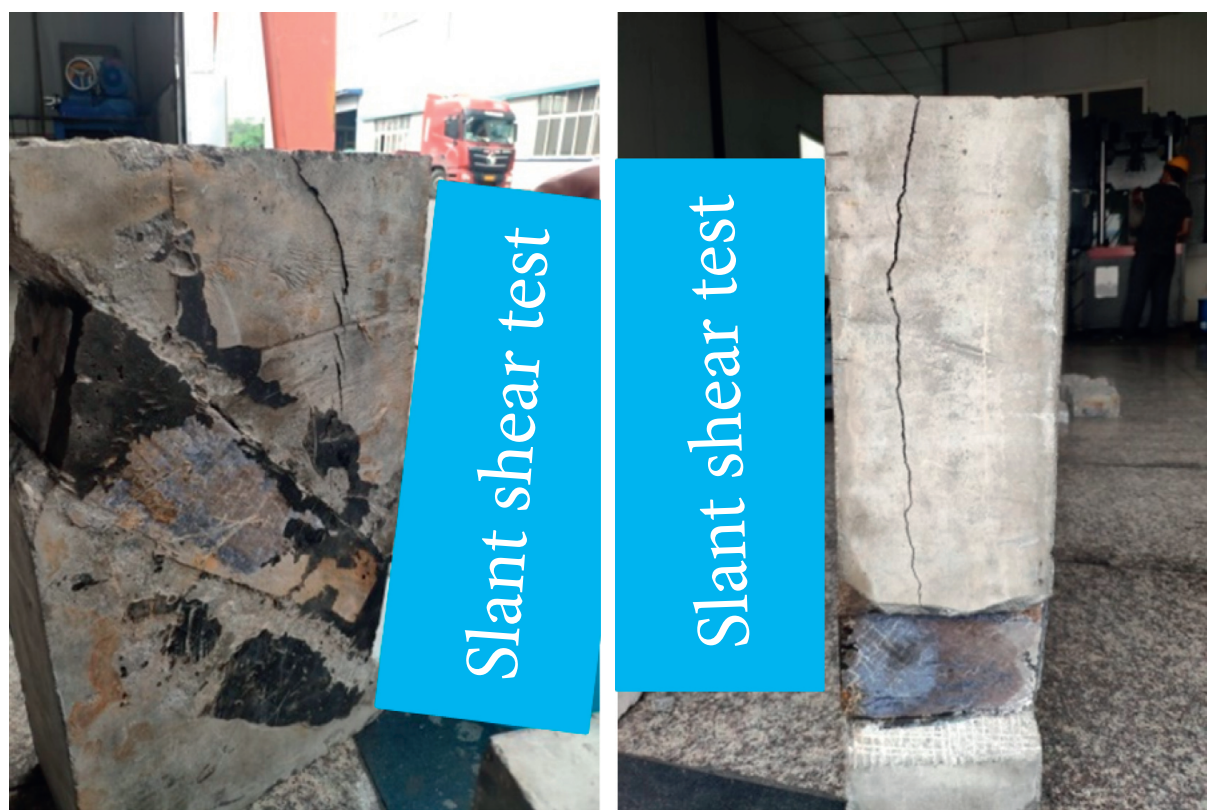

Figure 11: The failure mode of slant shear test specimen 3.

TABle 6: Friction coefficient under different stress status.

\begin{tabular}{lccccc}
\hline Sample & $\begin{array}{c}\text { Shear stress acting on the } \\
\text { bond interface, } \tau_{n},(\mathrm{MPa})\end{array}$ & $\begin{array}{c}\text { Bonding stress under } \\
\text { pure shear, } c(\mathrm{MPa})\end{array}$ & $\begin{array}{c}\text { Normal stress acting on the } \\
\text { bond interface, } \sigma_{n}(\mathrm{MPa})\end{array}$ & $\begin{array}{c}\text { Direct tension } \\
\text { tensile bond } \\
(\mathrm{MPa})\end{array}$ & $\begin{array}{c}\text { Friction coefficient, } \mu \\
\text { Minimum }\end{array}$ \\
Average & 3.19 & 1.71 & 3.19 & 0.72 & 0.48 \\
Best fit & 5.20 & 1.82 & 5.20 & 0.65 \\
Best fit $^{2}$ & & 1.57 & & 0.74 \\
Best fit $^{3}$ & & 0.68 & & 0.89 \\
\hline
\end{tabular}




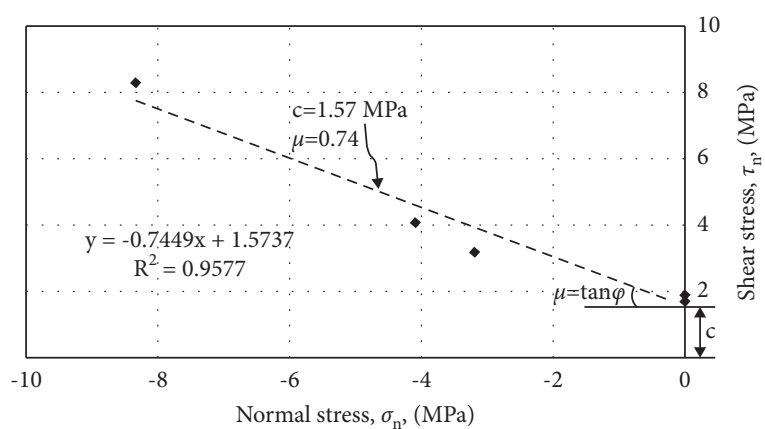

(a)

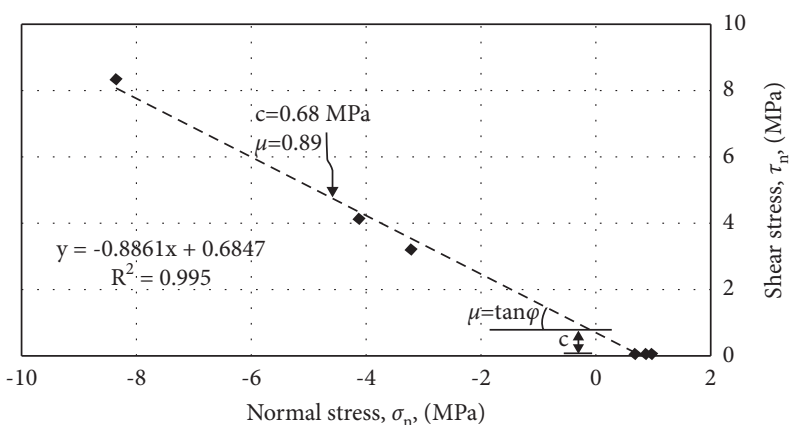

(b)

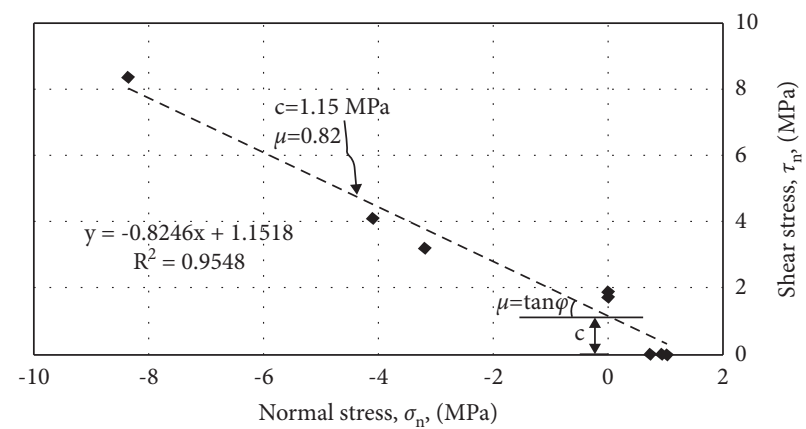

(c)

Figure 12: Experimental shear-normal stress interaction and linear extrapolation. (a) Push-off and slant shear. (b) Direct tension and slant shear. (c) Direct tension, push-off, and slant shear.

the concrete strength. Thus, the authors recommend that the further studies for the bonding strength of ERC-NSC interface should consider the aforementioned parameters to check the applicability of cohesion and the friction coefficients.

In this investigation, the bonding strengths are determined by direct tension, push-out, and slant shear tests. It is crucial to evaluate if these bonding strengths are correlated. Semendary and Svecova [36] determined the cohesion coefficient for UHPC-NSC interface with dry and saturated surface dry (SSD) from the modified Coulomb theory and the minimum values were $2.78 \mathrm{MPa}$ for both moistures, while the shear friction coefficients were 1.33 and 1.32, respectively. Moreover, the linear regression was introduced to analyze the experimental results from different stress combinations and compare the cohesion and friction coefficient values. They conducted that cohesion values generated by direct shear stress were less than those of the direct tensile stress and the friction calculated from involving the direct tension was slightly less than that from the mean or minimum bonding strength.

Similar to the data analysis methods of above researchers, a simple linear fit was used to analyze the threetype combined data: (1) slant shear and push-out tests; (2) slant shear and direct tension tests; and (3) push-out and direct tension tests. The cohesion coefficients and friction were extrapolated for the all data points from shear-normal stress interaction. As shown in Figures 12(a)-12(c), there was very high correlation in all the tests. The cohesion and friction coefficients from best linear fitting are presented in
Table 6. The findings show that cohesion value and friction coefficient from the data of push-out and slant shear tests were $1.57 \mathrm{MPa}$ and 0.74 , while the values from the data of tension and slant shear test were $0.68 \mathrm{MPa}$ and 0.89 , respectively. Combining the data of the three tests, the cohesion value and friction coefficient were $1.15 \mathrm{MPa}$ and 0.82 . It is noteworthy that when the direct tension measurements were involved, the cohesion was the lowest and the friction coefficient was the highest compared particularly with the pure shear results.

It is worth noting that the cohesiveness was lower and the friction coefficient, especially when compared to pure shear findings, was the most significant when direct tension measurements were added.

Based on the NSC substrate and ERC overlay combination specimens, this paper studied these two coefficients. The test results of the push-out test are used to define the experimental value of the cohesion coefficient. As shown in Table 6 , the friction coefficients were determined by equation (4) and the experimental results or using linear regression under different stress combinations. The results show that cohesion values of the interface from push-out test are marginally higher than those from direct tension. However, the friction considering direct tension is higher than that from average or minimum bonding strength. The results are different from those found in Ali A. Semendary's paper [36].

Therefore, the current study confirms that the linear fit considering the direct tensile test provides a conservative value for cohesion, while the linear fit including the push-out test provides a conservative value for friction coefficient. 


\section{Conclusions}

The current study concentrated on the interfacial bonding performances between epoxy resin concrete (ERC) and Grade-50 normal strength concrete (NSC) by the direct tensile test, push-out test, and slant shear test. These specially designed specimens' size and methods in this paper were feasible. Some conclusions can be taken from the discussions above:

(1) There are obvious differences in the bonding strengths from 3 different tests. The direct tensile bonding strength was $0.72-1.0 \mathrm{MPa}$, the push-out bonding strength was $1.71-1.89 \mathrm{MPa}$, and the slant shear bonding strength was $3.19-8.33 \mathrm{MPa}$. The bonding strengths from slant shear test are the highest, followed by the values of push-out test, and the bonding strengths of direct tensile test are the lowest.

(2) In the slant shear test with an inclination angle of $45^{\circ}$, it is difficult to cause failure at the bonding interface of specimens due to due to the large compressive stress acting on the bond interface. Only a lower bonding limitation has been evaluated for the interfacial bond performance in slant shear test as a result of unanticipated substrate failure.

(3) Based on the modified Coulomb theory, the linear fitting deduced that the minimum value of cohesion was $1.71 \mathrm{MPa}$, and the average value was $1.82 \mathrm{MPa}$; the minimum value of friction coefficient was 0.46 , and the average value was 0.65 .

The future research will consider the aspects affecting the interface bonding capability of epoxy resin concrete (ERC) and normal strength concrete (NSC) and the relative influence rules.

\section{Data Availability}

The displacement curves of specimen failure load (figures) used to support the findings of this study are included within the article. The data used to support the findings of this study are available from the corresponding author upon request.

\section{Conflicts of Interest}

The authors declare that they have no conflicts of interest regarding the publication of this paper.

\section{Authors' Contributions}

Nannan Sun is the main author and experimenter of this article. Yifan Song, author 1's supervisor, provided guidance and research funding for the research. Wei Hou, corresponding author, was responsible for the main revision and responses of the article. Hanhao Zhang participated in experiment and data and image processing in papers. Datong $\mathrm{Wu}$ provided epoxy resin raw materials and assisted in the research of epoxy resin mix ratio and the bonding experiments in this article. Yuan Li, Principal of the Natural
Science Basic Research Program of Shaanxi (Grant no. 2020JQ-377), provided research funding, test equipment, and other test-related material resources. Yuan Gong provided technical support for testing and contributed to the research of resin epoxy concrete mix ratio, casting test specimens, designing, and manufacturing test setups.

\section{Acknowledgments}

This study was sponsored by the Natural Science Basic Research Program of Shaanxi (Grant no. 2020JQ-377). The financial support is gratefully appreciated. The assistance for experimental studies from China Chengdu Datong Road Bridge Machinery Company Limited, Chang'an University, is also appreciated. The China Scholarship Council is acknowledged for the financial support and assistance to the first author.

\section{References}

[1] Y. J. Jin and L. G. Xiao, "Research status and application of epoxy resin concrete," Journal of Jilin Construction Engineering, no. 1, pp. 37-40, 2011.

[2] Ministry of Transport of the People's Republic of China, Standard Test Method of Bitumen and Bituminous Mixtures for Highway Engineering (JTG E20-2011), Ministry of Transport of the People's Republic of China, Beijing, China, 2011.

[3] J. Tatar, C. Weston, P. Blackburn, and H. R. Hamilton, "Direct shear adhesive bond test," in Proceedings of the 11th International Symposium of fiber Reinforced Polymer for Reinforced concrete Structures (FRPRCS-11), Guimaraes, Portugal, June 2013.

[4] J. Tatar, N. R. Brenkus, G. Subhash, C. R. Taylor, and H. R. Hamilton, "Characterization of adhesive interphase between epoxy and cement paste via Raman spectroscopy and mercury intrusion porosimetry," Cement and Concrete Composites, vol. 88, pp. 187-199, 2018.

[5] F. Djouani, C. Connan, M. Delamar, M. M. Chehimi, and K. Benzarti, "Cement paste-epoxy adhesive interactions," Construction and Building Materials, vol. 25, no. 2, pp. 411423, 2011.

[6] A. Stewart, B. Schlosser, and E. P. Douglas, "Surface modification of cured cement pastes by silane coupling agentsfication of cured cement pastes by silane coupling agents," ACS Applied Materials \& Interfaces, vol. 5, no. 4, pp. 1218-1225, 2013.

[7] Ministry of Transport of the People's Republic of China, Test Methods of Cement and Concrete for Highway Engineering (JTG E30-2005), Ministry of Transport of the People's Republic of China, Beijing, China, 2005.

[8] J. P. Gorninski, D. C. Dal Molin, and C. S. Kazmierczak, "Study of the modulus of elasticity of polymer concrete compounds and comparative assessment of polymer concrete and portland cement concrete," Cement and Concrete Research, vol. 34, no. 11, pp. 2091-2095, 2004.

[9] W. Lokuge and T. Aravinthan, "Effect of fly ash on the behaviour of polymer concrete with different types of resinfly ash on the behaviour of polymer concrete with different types of resin," Materials \& Design, vol. 51, pp. 175-181, 2013.

[10] E. Ozeren Ozgul and M. H. Ozkul, "Effects of epoxy, hardener, and diluent types on the workability of epoxy mixtures," 
Construction and Building Materials, vol. 158, pp. 369-377, 2018.

[11] J. M. L. Reis and A. J. M. Ferreira, "The effects of atmospheric exposure on the fracture properties of polymer concrete," Building and Environment, vol. 41, no. 3, pp. 262-267, 2006.

[12] L. Agavriloaie, S. Oprea, M. Barbuta, and F. Luca, "Characterisation of polymer concrete with epoxy polyurethane acryl matrix," Construction and Building Materials, vol. 37, pp. 190-196, 2012.

[13] M. E.-H. Moetaz and A. F. Hisham, "Temperature effect on the mechanical behavior of resin concrete," Construction and Building Materials, vol. 14, pp. 317-323, 2000.

[14] M. U. Haddad, D. W. Fowler, and R. D. Paul, "Factors affecting the curing and strength of polymer concrete," ACI Structural Journal, pp. 396-402, 1983.

[15] C. Vipulanandan and E. Paul, "Characterization of polyester polymer and polymer concrete," Journal of Materials in Civil Engineering, vol. 5, no. 1, pp. 62-82, 1993.

[16] J. Shao, Z. Han, X. Zuo et al., "Effect of waste rubber particles on the mechanical performance and deformation properties of epoxy concrete for repair," Construction and Building Materials, vol. 241, pp. 1-12, 2020.

[17] Y. Jeong, M. M. Lopez, and C. E. Bakis, "Effects of sustained loading and temperature on a concrete-epoxy bonded interface," Journal of Materials in Civil Engineering, vol. 32, Article ID 04020016, 13 pages, 2020.

[18] I.-T. Roh, K.-C. Jung, S.-H. Chang, and Y.-H. Cho, "Characterization of compliant polymer concretes for rapid repair of runways," Construction and Building Materials, vol. 78, pp. 77-84, 2015.

[19] D. Lau and O. Büyüköztürk, "Fracture characterization of concrete/epoxy interface affected by moisture," Mechanics of Materials, vol. 42, no. 12, pp. 1031-1042, 2010.

[20] A. Zhou, O. Büyüköztürk, and D. Lau, "Debonding of concrete-epoxy interface under the coupled effect of moisture and sustained load," Cement and Concrete Composites, vol. 80, pp. 287-297, 2017.

[21] K.-C. Jung, I.-T. Roh, and S.-H. Chang, "Stress analysis of runway repaired using compliant polymer concretes with consideration of cure shrinkage," Composite Structures, vol. 119, pp. 13-23, 2015.

[22] K.-C. Jung and S.-H. Chang, "Evaluation of shrinkage-induced stress in a runway repaired using compliant polymer concrete," Composite Structures, vol. 158, pp. 217-226, 2016.

[23] C. Zanotti and N. Randl, "Are concrete-concrete bond tests comparable?" Cement and Concrete Composites, vol. 99, pp. 80-88, 2019.

[24] D. S. Santos, P. M. D. Santos, and D. Dias-da-Costa, "Effect of surface preparation and bonding agent on the concrete-toconcrete interface strength," Construction and Building Materials, vol. 37, pp. 102-110, 2012.

[25] Y. He, X. Zhang, R. D. Hooton, and X. Zhang, "Effects of interface roughness and interface adhesion on new-to-old concrete bonding," Construction and Building Materials, vol. 151, pp. 582-590, 2017.

[26] P. Santos and E. Júlio, "Factors affecting bond between new and old concrete," Aci Materials Journal, vol. 108, no. 4, pp. 449-456, 2011.

[27] F. Ceia, J. Raposo, M. Guerra, E. Júlio, and J. de Brito, "Shear strength of recycled aggregate concrete to natural aggregate concrete interfaces," Construction and Building Materials, vol. 109, pp. 139-145, 2016.

[28] P. M. D. Santos and E. N. B. S. Júlio, "A state-of-the-art review on shear-friction,” Engineering Structures, vol. 45, pp. 435-448, 2012.
[29] D. K. Harris, M. A. Carbonell, A. Gheitasi, T. M. Ahlborn, and S. V. Rush, "The challenges related to interface bond characterization of ultra-high-performance concrete with implications for bridge rehabilitation practices," Advances in Civil Engineering Materials, vol. 4, 2014.

[30] H. H. Hussein, K. K. Walsh, S. M. Sargand, and E. P. Steinberg, "Interfacial properties of ultrahigh-performance concrete and high-strength concrete bridge connections," Journal of Materials in Civil Engineering, vol. 28, no. 5, pp. 04015208-1-04015210, 2016.

[31] B. A. Tayeh, B. H. A. Bakar, M. A. M. Johari, and Y. L. Voo, "Evaluation of bond strength between normal concrete substrate and ultra high performance fiber concrete as a repair material," Procedia Engineering, vol. 54, pp. 554-563, 2013.

[32] M. A. C. Munoz, D. K. Harris, T. M. Ahlborn, and D. C. Froster, "Bond performance between ultra-high-performance concrete and normal-strength concrete," Journal of Materials in Civil Engineering, vol. 26, no. 8, pp. 839-844, 2014.

[33] I. De la Varga, Z. B. Haber, and B. A. Graybeal, "Enhancing shrinkage properties and bond performance of prefabricated bridge deck connection grouts: material and component testing," Journal of Materials in Civil Engineering, vol. 30, no. 4, pp. 04018053-4018061, 2018.

[34] Z. B. Haber, I. De la Varga, B. A. Graybeal, B. Nakashoji, and R. El-Helou, Properties and Behavior of UHPC-Class Materials (No. FHWA-HRT-18-036), United States, Federal Highway Administration, Office of Infrastructure, Research and Development, Washington, DC, USA, 2018.

[35] M. Farzad, M. Shafieifar, and A. Azizinamini, "Experimental and numerical study on bond strength between conventional concrete and Ultra High-Performance Concrete (UHPC)," Engineering Structures, vol. 186, pp. 297-305, 2019.

[36] A. A. Semendary and D. Svecova, "Factors affecting bond between precast concrete and cast in place ultra high performance concrete (UHPC)," Engineering Structures, vol. 216, Article ID 110746, 2020.

[37] Y. Zhang, P. Zhu, Z. Liao, and L. Wang, "Interfacial bond properties between normal strength concrete substrate and ultra-high performance concrete as a repair material," Construction and Building Materials, vol. 235, Article ID 117431, 2020.

[38] American Concrete Institute (ACI), Guide For the Selection of Materials for the Repair of Concrete, American Concrete Institute, Farmington Hills, MI, USA, ACI 546.3R-06, 2006.

[39] American Association of State Highway and Transportation Officials, "Load and resistance factor design (AASHTO, LRFD)," Bridge Design Specifications, AASHTO, Washington, DC, USA, 5th edition, 2010. 